\title{
Application of RFM principles: What to do with 1-1-1 customers?
}

Received: 12th March, 2002

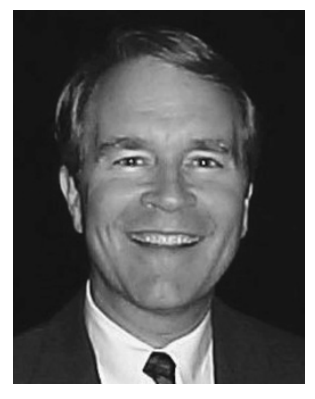

\section{John Miglautsch}

is founder of Miglautsch Marketing, Inc. which providers database marketing consultation. Their Model-to-Mail ${ }^{\mathrm{TM}}$ system allows ordinary marketing people to dramatically increase profits by understanding key opportunities to improve their marketing strategies and tactics.

John holds a BA and MA from the University of Wisconsin and PDM from the University of Missouri. He was a major contributor to the 8th Edition of Successful Direct Marketing Methods. In 1995, he founded the International Society for Strategic Marketing, Ltd. with members in over 70 countries.

Abstract Inherent in the basics of RFM are built its fundamental limitations. RFM alone by definition cannot move beyond this point. Segmentation of 1-1-1 requires the creation of additional variables. As you attempt to move beyond the 1-1-1s, and as your variables proliferate, you will find it necessary to understand automated analysis. As you investigate this process, remember, the 1-1-1s are your biggest customer segment and probably your greatest untapped potential.

\section{INTRODUCTION}

Recency, frequency, monetary (RFM) scoring has been the foundation of most direct marketing segmentation for decades. Consistently, the most recent buyers out-perform all others, multi-buyers (who have a purchase frequency greater than once) beat one-time buyers and, at the bottom of the segmentation chain, the remainder can be sorted by life-to-date monetary sales. And as long as the world moves along at a steady pace, the methodology seems repeatedly to select the better customers. This paper looks beyond common acceptance and examines areas of weakness in RFM.

John R. Miglautsch Miglautsch Marketing Inc, W226 N555 Eastmound Drive, Ste. E, Waukesha, WI 53186-048, USA.

Tel: +1 2625425633 ; Fax: +1 262542 2066; e-mail: john@migmer.com

\section{LIMITATIONS OF RFM}

Although RFM has been widely used, ${ }^{1}$ it nevertheless has significant limitations. RFM is based on buying behaviour - when and how much has been bought. Consequently, it focuses, almost exclusively, on the best customers. As discussed in an earlier paper, ${ }^{2}$ meaningful scoring must focus on significant differences in customer behaviour. Applying this method to frequency, many cases are seen where more than 50 per cent of customers have only purchased once. If the single/multi-buyer variable is considered in the selection, there is very little choice, it is either to mail the 50 per cent or not. Recency and monetary value can be applied but this helps very little. Most mailers find that over 50 per cent of their customers place very small orders. These customers form the overwhelming majority of the one-time buyers. Recency helps slightly, if a company is new and growing rapidly. If, however, the business has been in existence a decade or more, it will again find that well over 50 per cent of its 
customers have not bought in the past

24 months. Hardly refined target

marketing.

The above case begins to describe the 1-1-1 customer, the one who does not buy often, spends little or has not bought lately (strictly speaking these are all 'and' conditions). As noted, these customers often make up 50 per cent of a mature customer file count. A possibility might be to consider revising scoring methods in order to create a finer grid through which to view segmentation decisions. But, as the case of frequency illustrates, introducing a customer split between groups which have both ordered exactly once would be confusing, distorting and completely inappropriate. It is the author's contention that RFM does not, within its own variables, provide the power to decide exactly what to do with this huge 1-1-1 customer lump. If the business has the money, then perhaps such customers should be contacted, if not, perhaps they should not. ${ }^{3}$

When RFM segmentation is used, significant numbers of customers are not contacted. RFM practitioners will typically trim the 1-1-1 group because they have not responded in two years or more of offers. The choice is often a painful one. When a company is new, all customers are also new. As long as substantial growth is maintained, new customers offset the small number of early customers who have not reordered. But as the number of 1-1-1 customers grow, the cost of contacting them makes their repeated re-contact increasingly unprofitable. Obviously, customers who are not contacted rarely respond. This tends to confirm the hypothesis that it was correct simply to eliminate large quantities of old customers.

The true focus of RFM is the top 20 per cent of the customer file - the 5-5-5s who have bought something in the current quarter, have bought regularly and spend lots of money. RFM zeros right in on these people. At the same time, any business paying any kind of attention will also spot these great customers. A relatively prosperous business mailer did not mail anyone after 12 months and only mailed the customer file four times per year. Whenever a customer ordered, however, they were sent a special catalogue. Another catalogue was inserted in the shipment. That meant that the 5-5-5s who ordered monthly would effectively receive 28 catalogues per year even though the business only had four main catalogue mailings. In the past 20 years, many very different customer contact strategies have been seen which similarly ignored RFM but nevertheless managed to contact the best customers more often than the worst.

If followed slavishly RFM almost guarantees smaller circulation. The $1-1-1$ s are simply too numerous, too expensive and too obvious to keep mailing. But that is the crux of the problem, if rational RFM scoring rightly groups large numbers of older, one time, less valuable customers together, how can the temptation simply to write them off and shrink the company be counteracted?

The data in Figure 1 and Table 1 (from a business-to-business catalogue company) reflect the wide skew towards poor RFM customers. 280M of the $354 \mathrm{M}$ are one-time buyers. Although recency is not quite as skewed, one-third of the customers have not purchased anything in the past 24 months.

The data in Figure 2 and Table 2 come from a consumer catalogue. Though the industries and markets vary widely and this company has a slightly narrower distribution of frequency over 50 per cent of the customers combine for a low frequency and low recency. As the chart illustrates, monetary is similarly skewed toward the low end. 1-1-1 


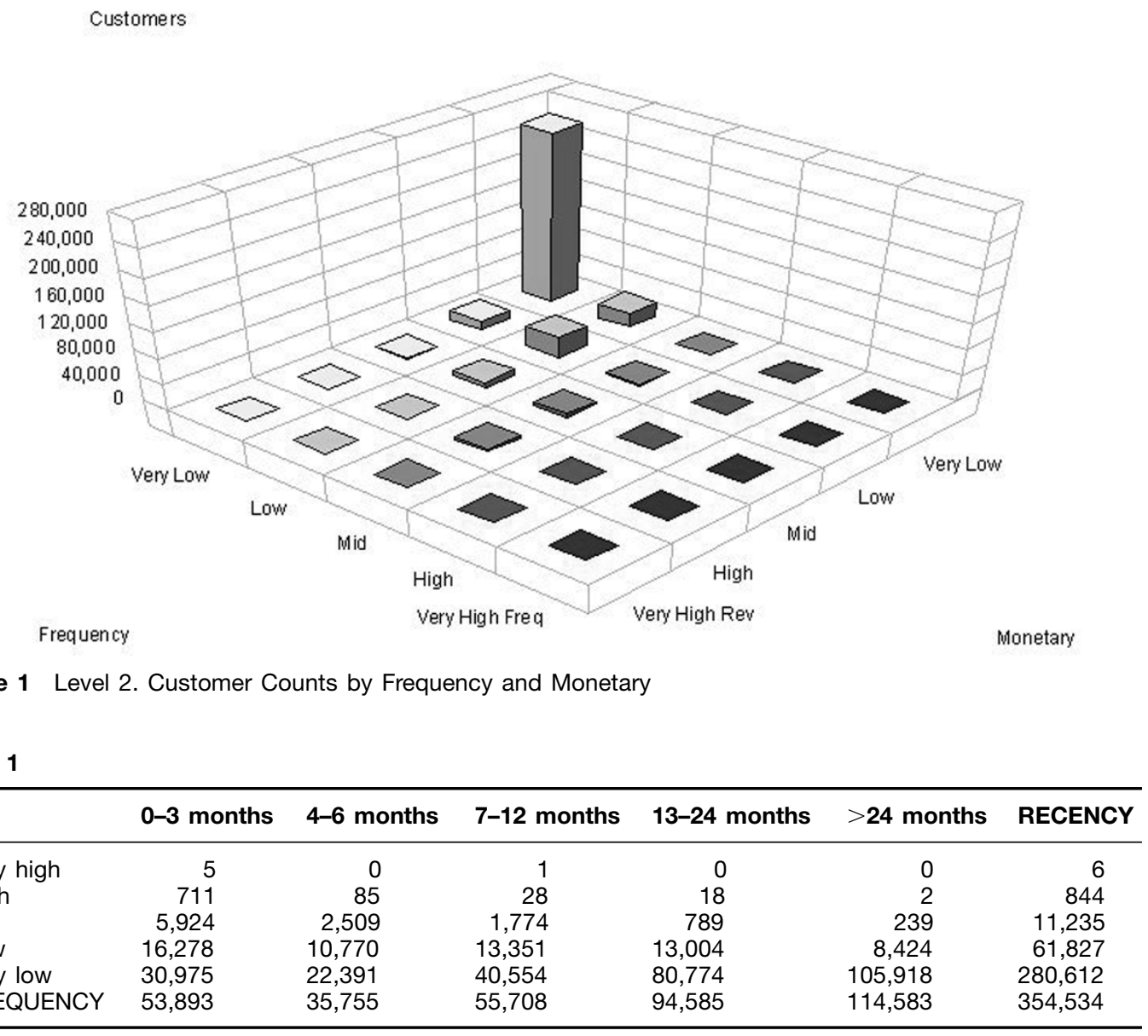

customers clearly dominate the segmentation and customer behaviour.

In applying RFM it is easy to reduce circulation and customer contact. As discussed, there is, however, little information on the lower segments of RFM 1-1-1s. Given the lack of information, it is relatively easy to reduce circulation, however it means eliminating the largest segment of customers from contact. Low RFM customers not contacted tend not to respond, therefore RFM tends to be self-fulfilling.

Most mailers contact the $1-1-1$ s at least 24 times as they slide down the recency scale for the two years after their initial purchase. It may be that they have been given more than enough opportunity to make a repeat purchase.
At the same time, it is not uncommon for customers to purchase durable goods which do not need replacing quickly. Small mailers know that if these older 1-1-1 customers were to be contacted, some purchases would be generated though not at a profitable response rate. The tension is between budgeting money to attempt to reactivate old $1-1-1 \mathrm{~s}$ and finding new customers via advertising and other direct marketing.

Companies which repeatedly mail the $1-1-1$ s find that they perform at or slightly below their best prospect lists. The business or household has had a demonstrated interest in the product. At the same time, the specific buyer may have moved or changed interests. If the marketer could peer into the individual 


\section{Customers}

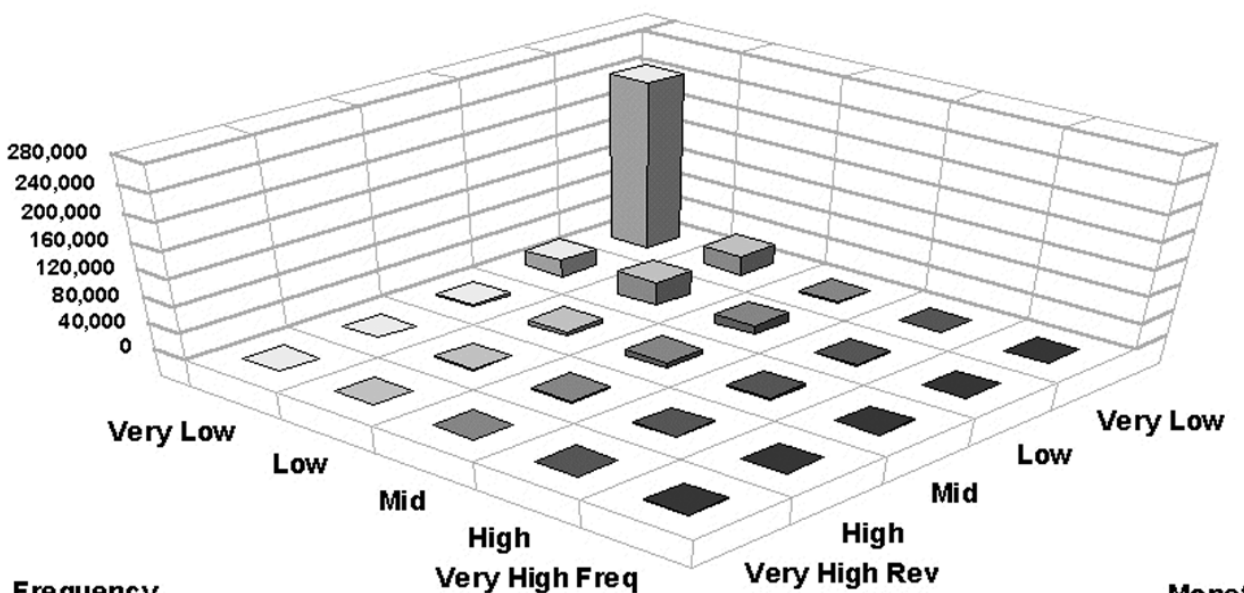

Frequency

Figure 2 Frequency - Monetary Counts

Table 2

\begin{tabular}{lccccrr}
\hline & 0-3 months & 4-6 months & 7-12 months & 13-24 months & > $\mathbf{2 4}$ months & RECENCY \\
\hline Very high & 760 & 341 & 397 & 304 & 264 & 2,066 \\
High & 1,527 & 1,111 & 1,487 & 1,340 & 1,585 & 7,050 \\
Mid & 3,858 & 2,870 & 4,756 & 5,460 & 8,875 & 25,765 \\
Low & 7,692 & 5,846 & 10,692 & 14,102 & 35,616 & 73,948 \\
Very low & 17,957 & 15,895 & 28,756 & 47,343 & 170,512 & 289,463 \\
FREQUENCY & 31,794 & 26,063 & 46,088 & 68,495 & 216,852 & 389,292 \\
\hline
\end{tabular}

realities, they might find a totally different set of people at that address. Mailing to them may prove completely futile. At the same time, 'birds of a feather flock together'. This particular address has some propensity toward similar interests simply because it is in a certain geodemographic strata.

As the 1-1-1s continue to age, however, they become increasingly unproductive, falling well below rented lists in performance. This is mainly due to the inability of standard RFM to adjust to the advancing age of the least responsive customers. Without adjustment, the average recency would increase indefinitely. Obviously, the solution is either to adjust the recency scoring or to reclassify the oldest customers as inactive. Strictly speaking, adding more recency bands will retain the 1-1-1 problem (but the meaning will change through time) so the author favours the reclassification approach.

Conventional wisdom says that it is better to retain a customer than to find a new one. ${ }^{4}$ Maximising customer retention and lifetime value is an industry mantra. In many product categories, however, most notably special interest hobbies (where people buy a large quantity of gear in the early stages), age-specific sports gear or high fashion (where people are continually looking for a 'new' experience), experience suggests that new customers can occasionally be far more profitable than long-time loyal customers. This issue is raised simply to 
suggest that many direct marketing companies find it acceptable to mail buyers repeatedly for 24 months (regardless of reorder). At some point (typically between 12 and 24 months), mailing frequency is reduced. Finally, at say 36 months, the customer is reclassified as dormant. At that point (or shortly before) some reactivation efforts are made. Dormant names may be matched against phone directories or response databases to determine contact information accuracy as well as competitive dormancy. Following those efforts the dormant customers may be inserted in the merge/purge as a suppress file (or in order to flag resurrection within net name agreements).

Nevertheless, reactivation strategies, though important, do not address what to do from a database standpoint while the customer is in the never-never-land between hotline buyer and dormant reclassification. Since the 1-1-1 segment is by far the largest (even where companies practise reclassification), if there were a way to peer into it, it could provide the greatest growth opportunity.

The fact is that when the $1-1-1$ s are contacted, they do produce orders. They may not be profitable after taking contact cost into account, but this indicates that there are viable customers buried in there (if only they could be found).

\section{OVERCOMING RFM LIMITATIONS: RFM EXTENSION}

In examining some of the challenges presented by the 1-1-1 segment, all the viable solutions offered have been to increase the complexity of the basic RFM segmentation system by creating additional variables. Those options included reclassifying old dormant customers (recency), selecting multi-buyers (frequency) or limiting selection to $1-1-1$ s with the greatest life-to-date purchases. In every case, the sensitivity of RFM is heightened by more carefully handling the continuous data that make up the RFM data.

Subsegmentation is the key to 1-1-1 viability and profitability. Unfortunately, again, RFM by itself is not designed to break up the $1-1-1$ s.

There are three main classes of variables which can be added to RFM to break up the 1-1-1s. The first is internal purchase information. This information consists of variables which can be created from the existing transaction data. In catalogue companies there are a wide variety of products which can be classified by an assortment of dimensions (ie price point, use, market and even what they are made of). There are an infinite number of product classification schemes. The most useful, however, identify something specific about the customer and their market or lifestyle.

The next class of variables is generated from geodemographic information connected to postal code. Since every customer has a postal code, these data have the advantage of being universal in their application to customers and prospects (people who have no purchase history). These are typically consumer variables usually based on national census information. Though they are specific to consumer income, dwelling value, family make up and occupation, they are applicable to both consumer and business-to-business analysis. They apply to business analysis because businesses are either directly tied to the economics of their community (ie restaurant or retail store) or they are national/international in marketing and not tied to their local economy (ie catalogue company, specialised consulting firm, etc.). In the second case, the company is located where it 
is because of the amenities of the community (still geodemographic in nature).

The final class is more difficult to define. The overall umbrella could be called custom variables. Typically, they are a combination of inside and outside data. As mentioned earlier, customers can be matched against outside data sources, either compiled or response databases. The downside of most outside matching is that fewer than 50 per cent of the customers match (even using phone numbers). That once again leaves large numbers of 1-1-1 customers unclassified. Then there is a wide array of options which can be related to customers by linking list counts and postal code data. Counts can be generated from any mailing list currently being used (with the list owner's permission of course). If one were mailing, say, the National Horse Owner's Association, that list could be broken down into count per postal code, density per postal code, percentage of population (or household) per postal code, etc. Counts by industrial classification are also available. This could generate variables such as riding stables per postal code. The important point is that these variables can be built from any list. They are built by comparison to good customers to determine penetration. Once found to be valuable they can be used to break up the 1-1-1s.

It is beyond the scope of this paper to examine the specifics of building and analysing these variables. Suffice to say there are an infinite number of possible variables. In a typical modelling process the author uses over 300 categorical variables for each customer (and there are a matching 300 continuous variables used to create those). Imagination and processing power are the only limits.

\section{CONCLUSION}

Inherent in the basics of RFM are its limitations. By definition, RFM alone cannot move beyond this point. Segmentation of the 1-1-1 group requires the creation of additional variables. In attempting to move beyond the $1-1-1 \mathrm{~s}$, and as the variables proliferate, the marketer will find it necessary to understand automated analysis. In investigating this process it is important to remember that the 1-1-1s are the biggest customer segment and probably represent the company's greatest untapped potential.

(C) John Miglautsch 2002

\section{References}

1 Catalog Age, April, 1999, reported that only 33 per cent of catalogue marketers in the USA had even RFM. That percentage had slipped from 35 per cent the year before.

2 Miglautsch, J. (2001) 'Thoughts on RFM scoring', Journal of Database Marketing, Vol. 8, No. 1, pp. 67-72.

3 Arthur Hughes, internationally-known database and RFM expert, commented privately that with the introduction of virtually free e-mail, RFM customer segmentation may become irrelevant. The author contends that there are additional considerations beyond cost. Time will certainly tell.

4 Reichheld, F. F. (1993) 'Loyalty-based management', Harvard Business Review, March-April, p. 66. 